\title{
Modelling and static analysis of femur bone by using different implant materials
}

\author{
Yegireddi Shireesha ${ }^{1}$, Dr S. V. Ramana ${ }^{2}$, P.Govinda Rao ${ }^{3}$ \\ ${ }^{1}$ PG Student, Department of Mechanical EngineeringGMR Institute of Technology, Rajam \\ ${ }^{2}$ professor,Department of Mechanical EngineeringGMR Institute of Technology, Rajam \\ ${ }^{3}$ Associate professor, Department of Mechanical EngineeringGMR Institute of Technology, Rajam
}

\begin{abstract}
Femur is leg bone of the human body Undergoing more deformation. Biomechanics is the theory of how tissues, cells, muscles, bones, organs and the motion of them and how their form and function are regulated by basic mechanical properties. The aim of this study is to create a model of real proximal human femur bone and the behavior of femur bone is analyzed in ANSYS under physiological load conditions.

A finite element model of bones is generated by using CT scan data are being widely used to make realistic investigations on the mechanical behavior of bone structures. . Orthopedic implantation is done in case of failure. Before implantation it is necessary to analyze the perfectness in case of its material property, size and shape, surface treatment, load resistance and chances of failure. Analysis is done for the stresses formed in different femur implant materials under static loading condition using ANSYS software.

Analysis is done on different materials like structural steel, and Ti-6Al-4V implant materials. Since each femur carries $1 / 2$ the body weight, analysis is done for $550 \mathrm{~kg}, 650 \mathrm{~kg}, 750 \mathrm{~kg}$ load, including the cases of patient carrying certain weight. And based on the analysis it can be concluded that, while comparing these two implant materials Ti-6Al-4V gave less deformation on static load conditions. TI-6ALAV is a low density material, which has excellent bio compatible and mechanical properties, it is ideal for the use of an implant in surgeries. Finally the success of implantation depends on implant material and size, implantation method and its handling by the patient.
\end{abstract}

Keywords: Biomechanics, Modeling, FEA, FEM, Femur

\section{Introduction}

Biomechanics is the application of mechanical principles on living organisms. By applying the laws and concepts of physics, biomechanical mechanisms and structures can be simulated and studied. Finite Element Method (FEM) is widely accepted as a power tool for biomechanics modeling. Irregular geometry, complex microstructure of biological tissues and loading situations are specific problems of the FEM in biomechanics and are still difficult to model. Straight beam theory is proposed to calculate stress distributions in the femur due to the body weight and some muscles force given some major simplifying assumptions on the muscles and the joint reactions. FE model would be advantageous in complementing experimental works

And in overcoming the inherent limitations associated with experimental studies which can provide only limited amount of information. Although some of these methods were found to provide enough automation, intrinsic accuracy, robustness and generality to be used in clinical applications. Hard tissues are rigid organs that form part of the endoskeleton of vertebrates. Bone tissue is a type of dense connective hard tissue. Bones is composed of inorganic salts impregnated in a matrix of collagen fibers, proteins and minerals. They maintain the shape of body and to assist in force transmission during movement. Long bones are characterized by a shaft, the diaphysis that is much longer than it is wide. The femur bone is the most proximal bone of the leg in vertebrates capable of walking or jumping. In human anatomy, the femur is the longest and largest bone but strongest under compression only. The femur at its bottom portion meshes with the tibia bone to create the knee joint. At its top end, the femur meshes with the acetabulum to create the hip joint. The femur is responsible for bearing the largest percentage of body weight during normal weight-bearing activities. The aim of this study is to create a model of human femur bone in CATIA software .

This model was analyzed in FEM package ANSYS 14.0.

This paper aims to construct a complete three-dimensional

Femur bone from CT scan data. The CATIA software is used to create 3D models and smooth the surface of the domain. The

Finite element method is applied to find the stress distribution and deformation on different implant materials at different load conditions . 


\section{Implants:}

An object made from non living material that is deliberately inserted by a surgeon into the human body where it is intended to remain for a significant period of time in order to perform a specific function. Despite great number of metals and alloys known to man, remarkably few warrant Preliminary consideration for use as implant materials. The relatively corrosive environment combined with the poor tolerance of the body to even minute concentrations of most metallic corrosion products eliminates from discussion most metallic materials. Of

The possible metallic candidates, tantalum and the noble metals do not have suitable mechanical properties for the construction of most orthopedic tools and implants, while zirconium is in

general too expensive Today, titanium, cobalt chrome, zirconium and stainless steel 316 are the most frequently used biomaterials for internal fixation devices because of a favorable combination of mechanical properties corrosion resistance and cost effectiveness when

Compared to other metallic implant materials. The biocompatibility of implant quality stainless steel has been proven by successful human implantation for decades. Composition, microstructure and tensile properties of titanium, cobalt chrome, zirconium and stainless steel 316 used for internal fixation is standardized in IS and ASTM material specifications. Metallurgical requirements are stringent to ensure sufficient corrosion resistance, nonmagnetic response,

And satisfactory mechanical properties. Torsional properties of stainless steel screws are different from titanium screws. Stainless steel bone screws are easier to handle because the surgeon can feel the onset of plastic deformation and this provides adequate pre-warning to avoid over-torquing the screw. New nickel-free stainless steels have been recently

Developed primarily to address the issue of nickel sensitivity. These stainless steels also have superior mechanical properties and better corrosion resistance. The Ni-free compositions appear to possess an extraordinary combination of attributes for potential implant applications in the future.

TABLE 1: Dimensions of femur bone:

\begin{tabular}{lc}
\hline \multicolumn{1}{c}{ Dimensions (millimetres) } & Mean \\
Femoral length & 443.6 \\
Femoral head offset & 47.0 \\
Femoral head diameter & 43.4 \\
Femoral head position & 56.1 \\
Canal width (lesser trochanter+20) & 43.1 \\
Canal width (lesser trochanter) & 27.9 \\
Canal width (lesser trochanter- 20) & 21.0 \\
Endosteal width at the isthmus level & 13.1 \\
Periosteal width at the isthmuslevel & 26.7 \\
Isthmusposition & 105.7 \\
Neck-shaft angle (degrees) & 122.9 \\
Canal flare index & 3.36 \\
\hline
\end{tabular}

\section{Modelling Of Femur Bone}

Figure 1 shows the schematic diagram of femur bone by using the above dimensions we design a real proximal femur bone using catia software fig 2:shows the modelled femur bone desiged from above data which was used in analysis part.:

Design Considerations: The material of the bone is anisotropic and not homogeneous, in the modeling, the bone was considered homogeneous and isotropic that does not exceed certain limits.

The bone is made by two kinds of materials compact and spongy, like a composite material. The avarage data of these materials are considerd while design a bone.

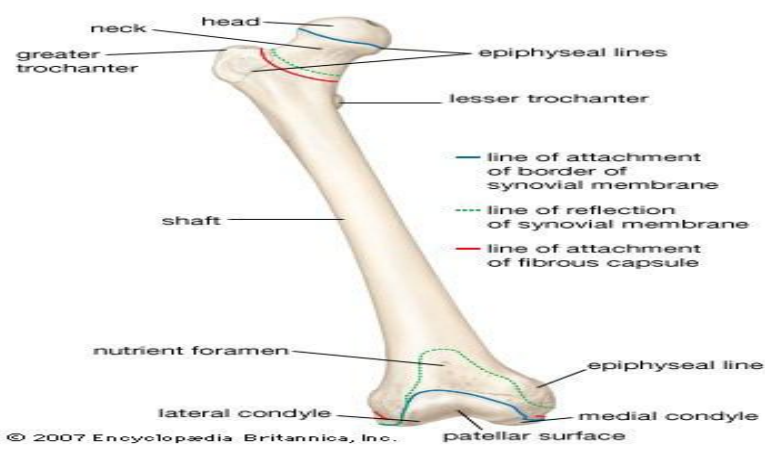

Figure 1: Schematic diagram of femur bone 

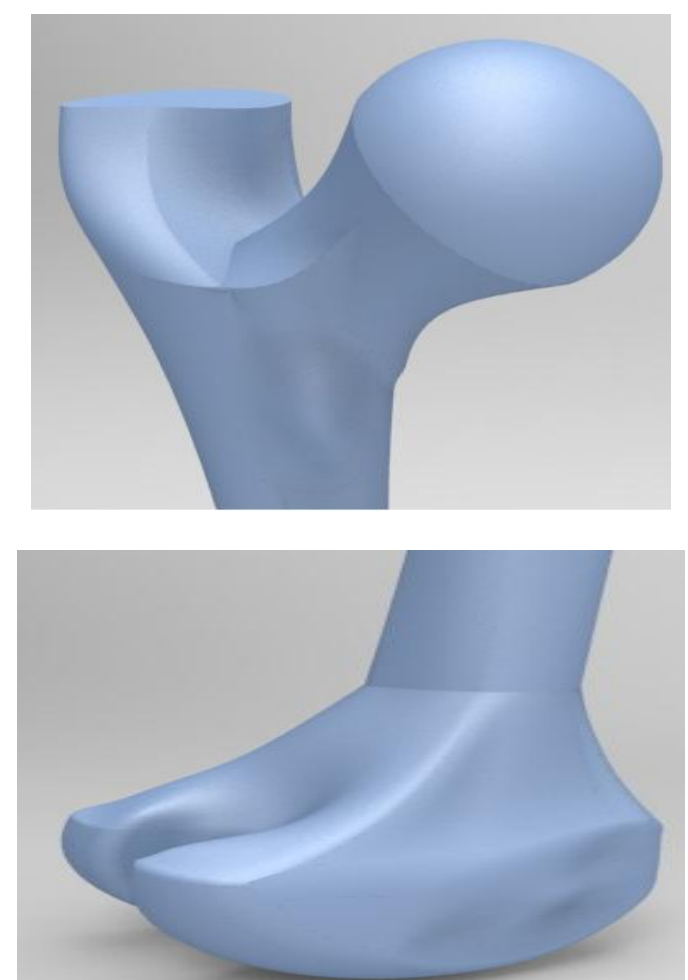

Figure 2: Modelling parts of femur bone

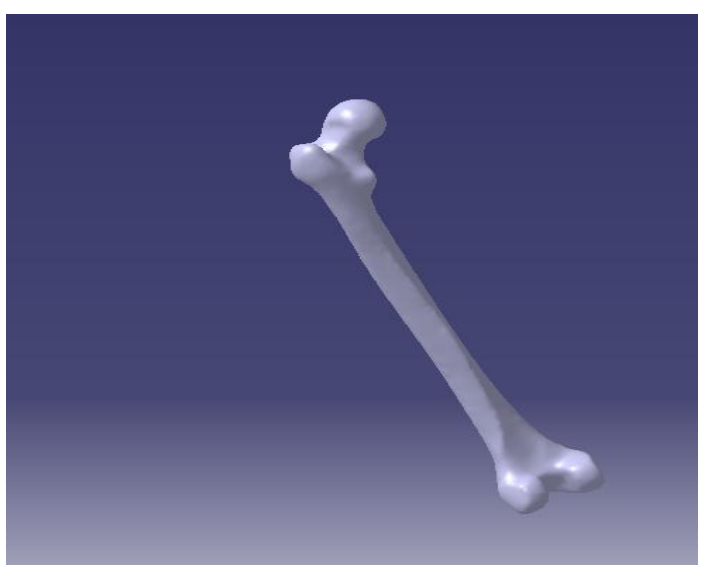

Figure 3 Schematic diagram of femur bone

For FE analysis of femur bone, firstly the three dimensional model of femur was developed. In early studies either a frozen bone, a wet bone, synthetic bone or a bone with apparent density was analyzed but here, geometrical data of real proximal human femur bone in the form of CT scan image format of 17 years old male, whose weight is $75 \mathrm{Kg}$ is obtained from CT scan is used. Digital Imaging and Communications in Medicine (DICOM) contains binary data elements. CT scan data in the form of DICOM consist of two-dimensional gray scaled images of a human male. The Hounsfield Unit corresponding to each element are averaged and converted into gray values and then to material properties of bone. CT images are a pixel map of the linear X-ray attenuation coefficient of tissue.

\section{Meshing:}

\section{ANALYSIS OF FEMUR BONE}

After creating model, for further Finite element analysis (FEA), surface mesh is generated for femur bone model. This surface mesh can be used to generate a volumetric mesh in FEA preprocessor. The volumetric mesh can be generated in ANSYS for the model of femur bone. The FEA software ANSYS14.0 was used for generating volumetric mesh. 


\section{Material Assignment}

Human bone is highly heterogeneous and nonlinear in nature, so it is difficult to assign material properties along each direction of bone model. In biomechanics study, material can be assign in two ways, either in Mimics or in Finite element module. Here material properties are directly assigned in ANSYS. The following properties of Density, Young's Modulus and Poisson's Ratio are used as $2000 \mathrm{Kg} / \mathrm{m} 3,2.130 \mathrm{GPa}$ and 0.3 respectively for analysis .

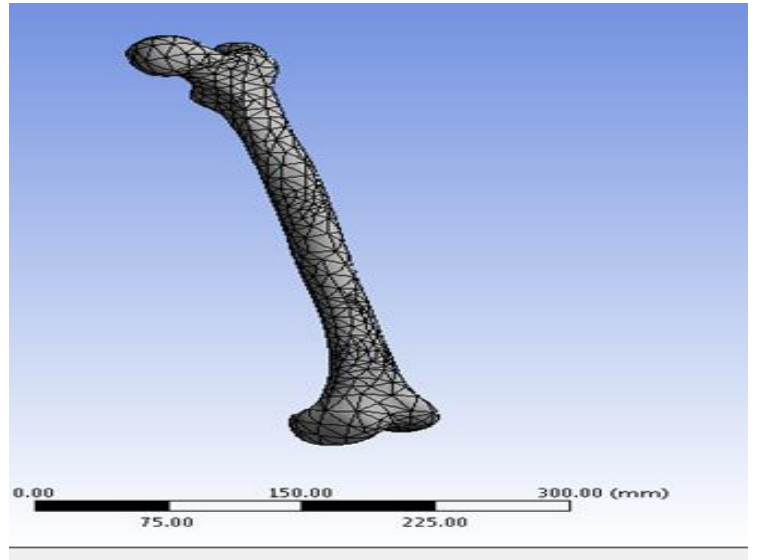

Figure 4: Mesh generation on femur

\section{Description of Model}

The three dimensional finite element model of femur bone consists of 4625 total numbers of nodes and 2435 numbers of elements in volumetric mesh. Three noded linear triangular element is used to element is used to create volumetric mesh in ANSYS14.0 having minimum edge length of $3.16940 \mathrm{~mm}$.

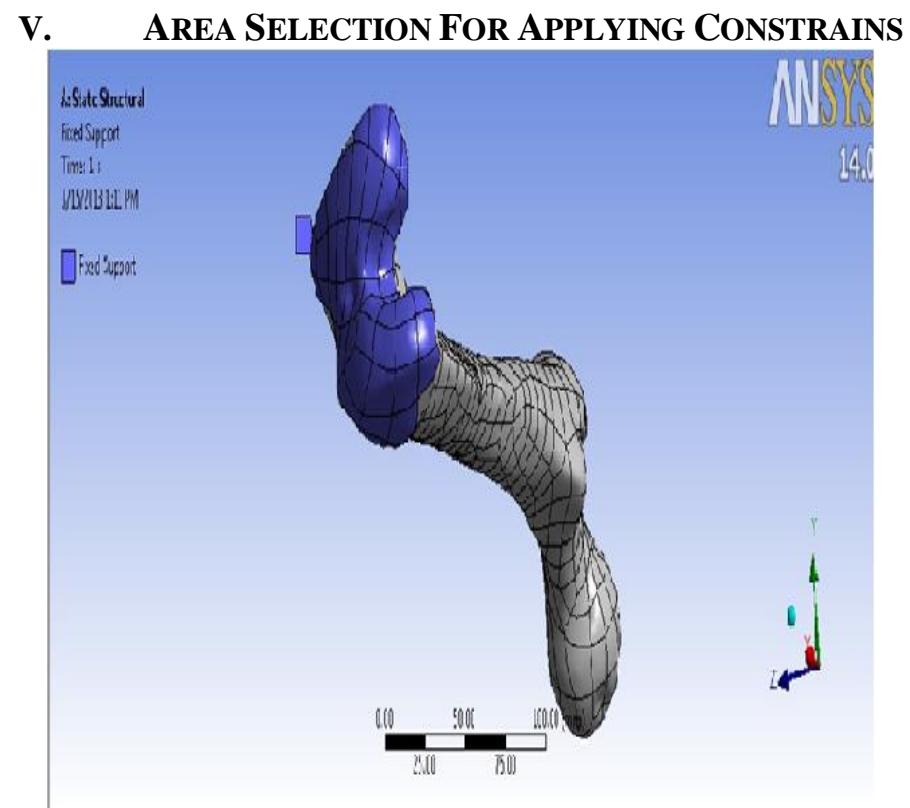

Figure 4: Constrains appication

\section{Boundary conditions:}

Femur bone is solid and inflexible. The three dimensional Finite element model of femur bone with volumetric mesh was imported in ANSYS. Since the femur bone model is nonlinear and highly heterogeneous in nature, model is first imported in Finite Element Modeler then transfer to static structural module in ANSYS 14.0. An eccentric and concentrate loads of $550 \mathrm{~kg}, 650 \mathrm{~kg}, 750 \mathrm{~kg}$ applied at the head of femur bone and hinged support is provided at lateral condyle, medial condyle and patellar surface. 


\section{Area Selection For Applying Pressure}

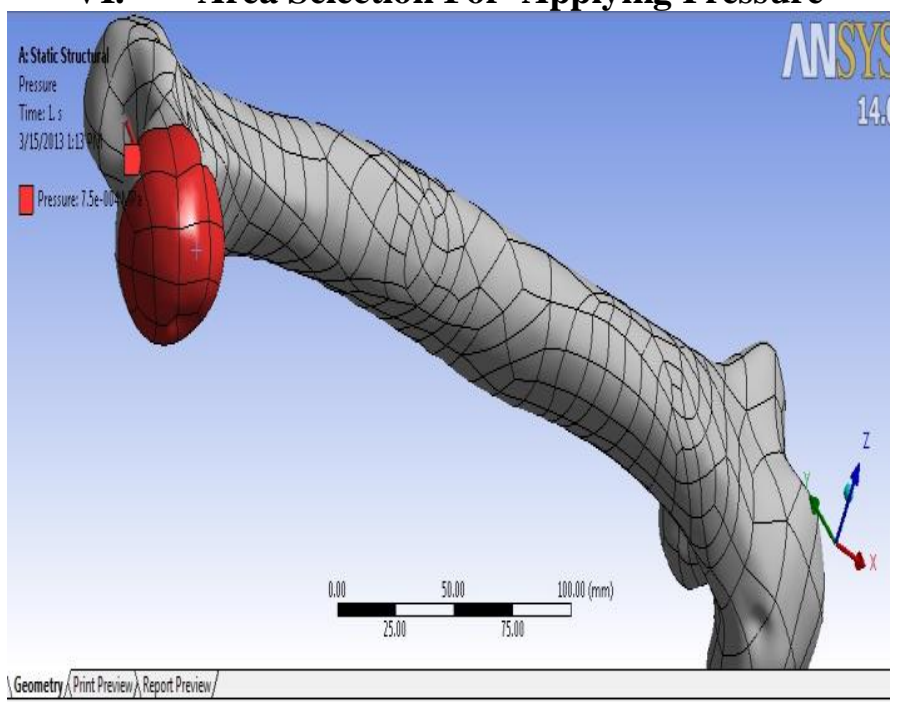

Figure 6:

ANALYSIS OF Ti-6Al-4V

for $550 \mathrm{~kg}$

Deformation in ti-6al-4v:

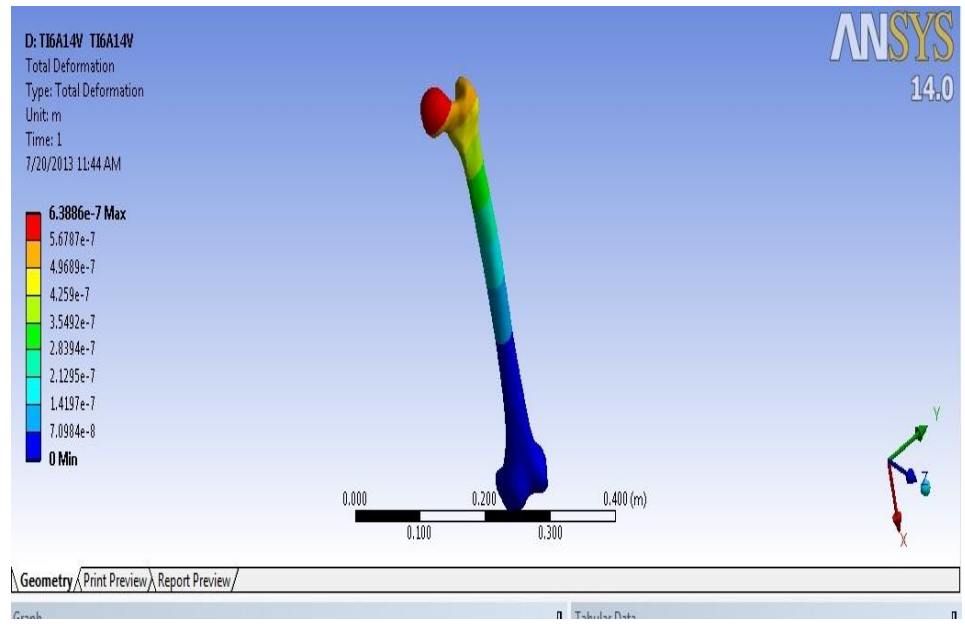

Fig7:Maximum deformation:0.00063886mm von-mises stress in ti-6al-4v:

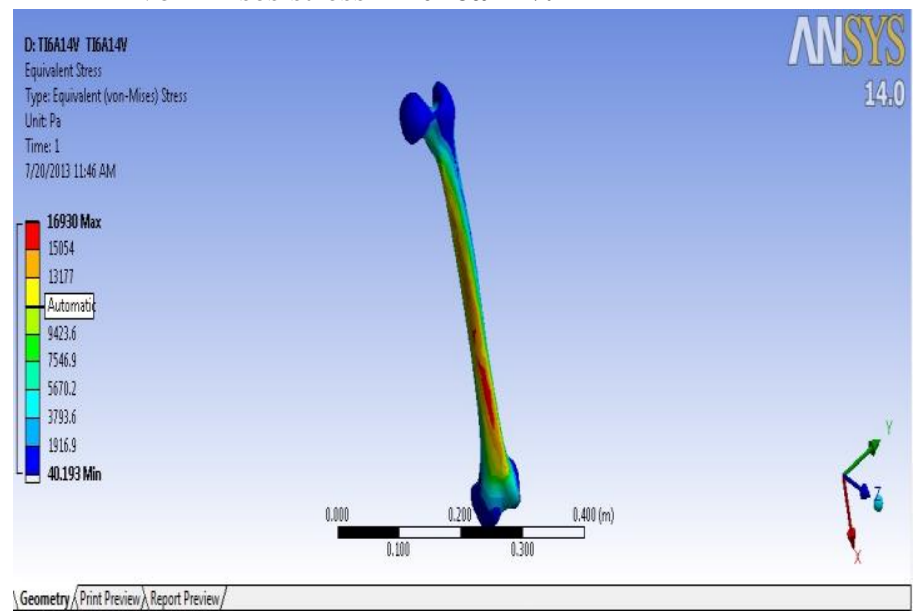

Figure 8: Max von-mises stresses in ti-6al-4v:0.01693mpa 


\section{for $650 \mathrm{~kg}$ :}

Deformation in ti-6al-4v:

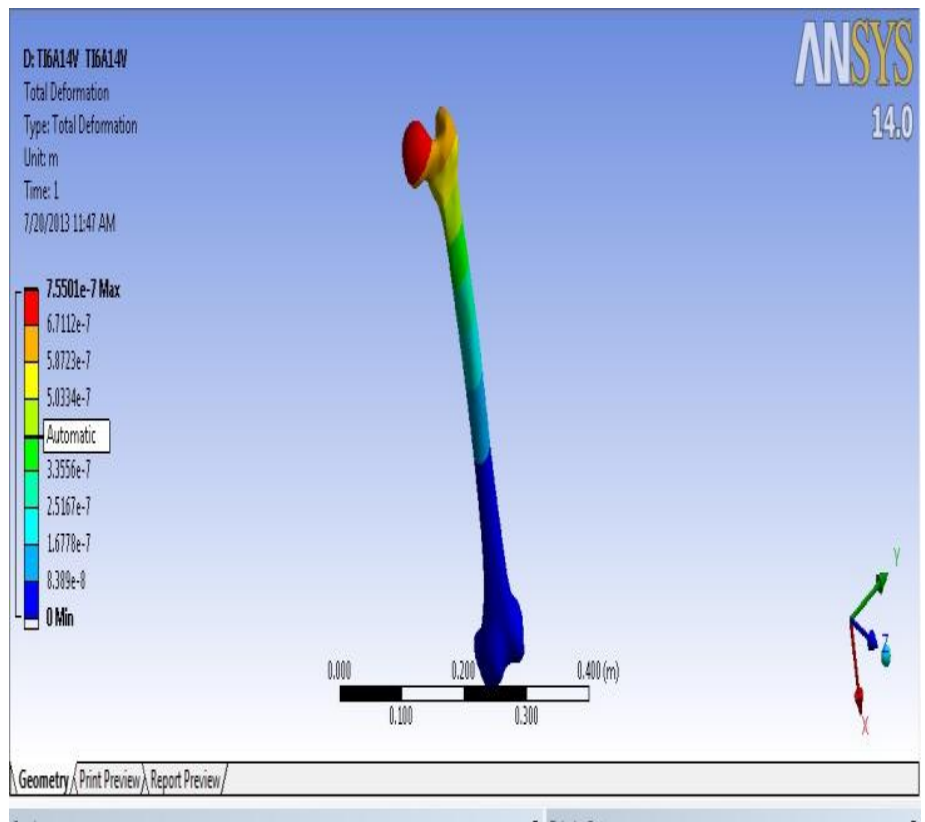

Fig9:Maximum deformation:0.00075501mm von-mises stress in ti-6al-4v:

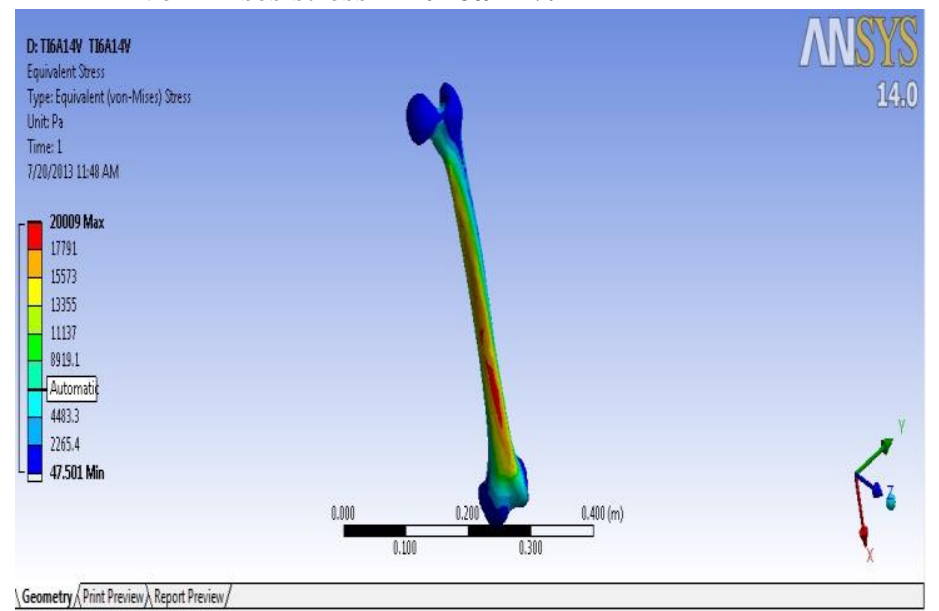

Figure 10: Max von-mises stresses in ti-6al-4v:0.20009mpa

$$
\text { For 750pa }
$$

Deformation in ti-6al-4v:

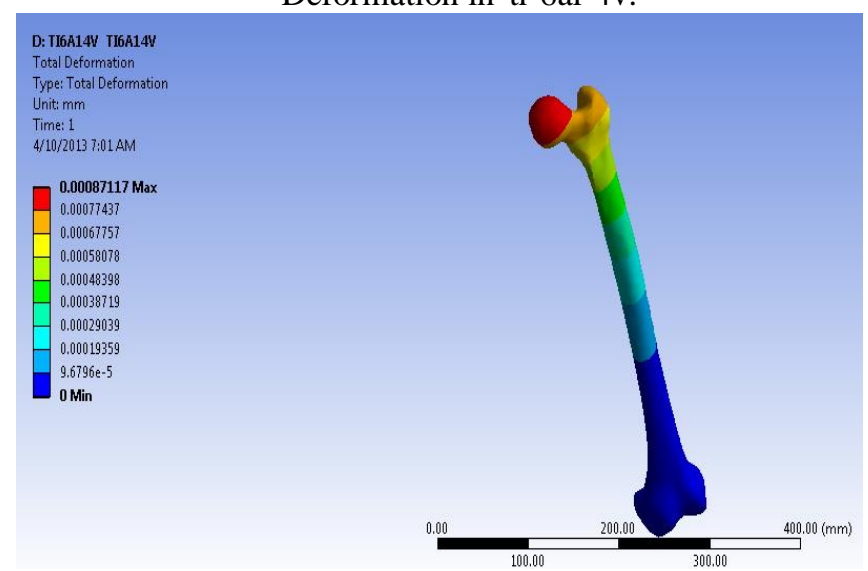

Fig7:Maximum deformation:0.00087117 mm 
von-mises stress in ti-6al-4v:

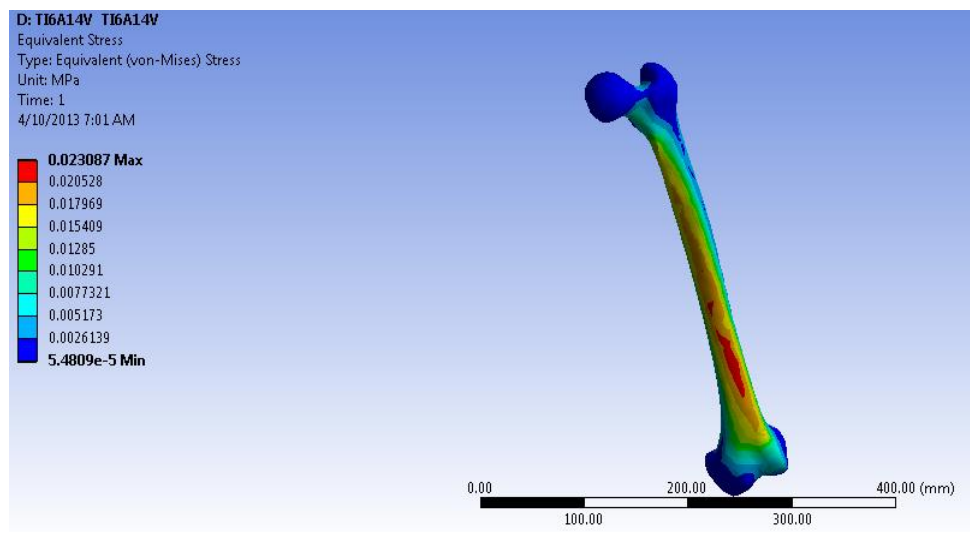

Figure 8: Max von-mises stresses in ti-6al-4v:0.023087mpa

\section{Analysis Of Structural Steel} for $550 \mathrm{~kg}$

deformation in structural steel:

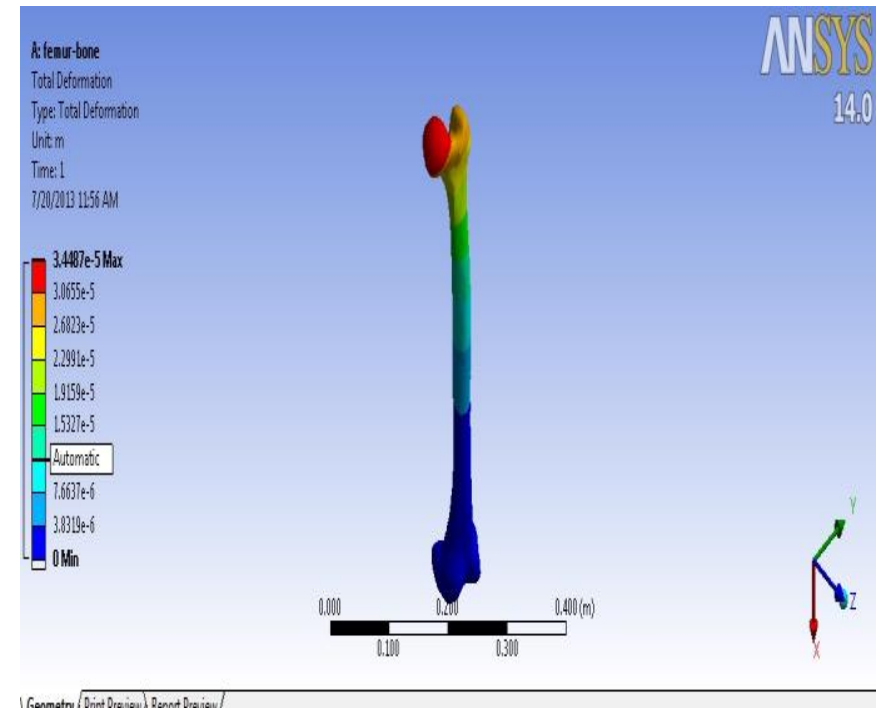

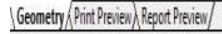

Figure 13: Maximum deformation:0.034487mm

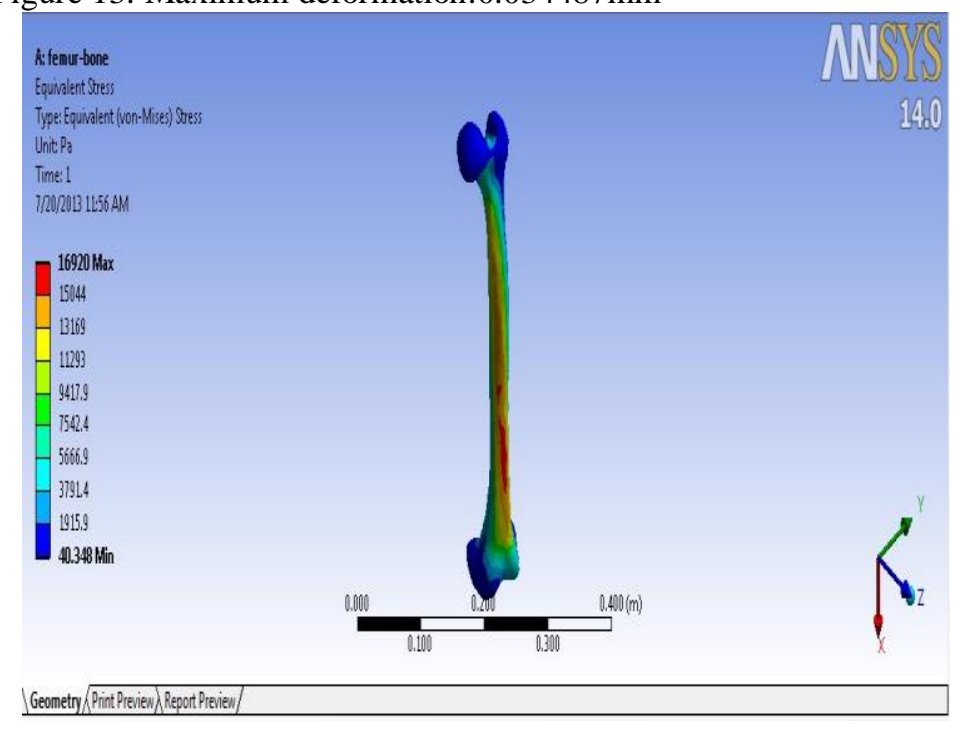

Figure14: Max von-mises stresses in structural steel:0.01692mpa 


\section{for $650 \mathrm{~kg}$}

deformation in structural steel

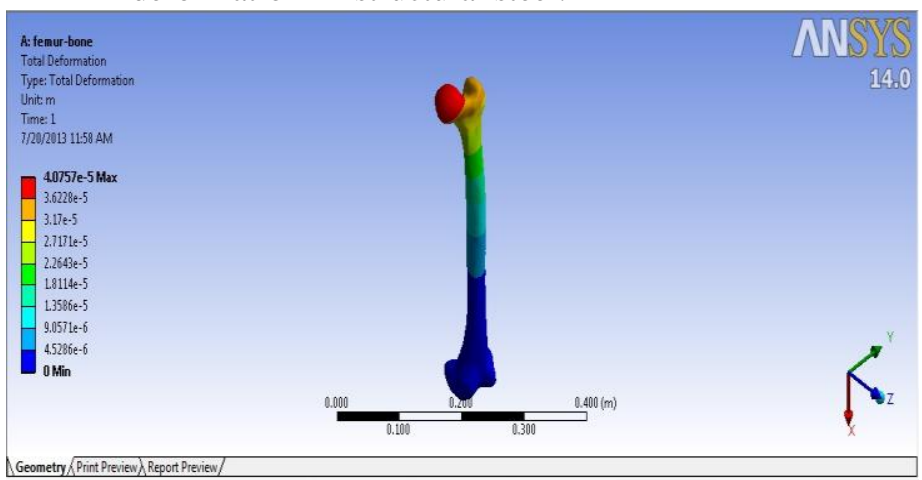

Fig15:Maximum deformation:0.040757 mm

von-mises stresses in structural steel:

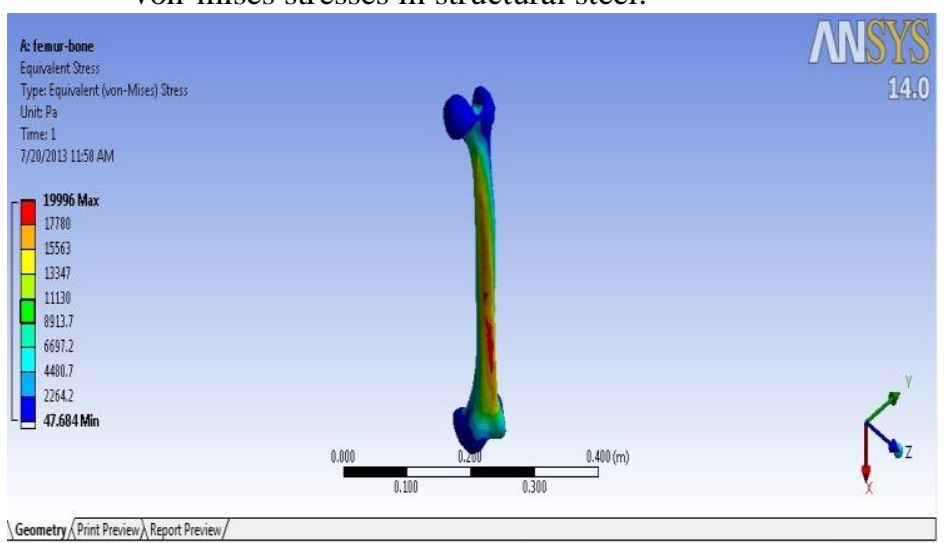

Figure 16:Max von-mises stresses in structural steel:0.019996mpa for 750kg:

deformation in structural steel:

A: femur-bone
Total Deformation
Type: Total Deformation
Unit: mm
Time: 1
3/5/2013 $11: 37$ PM
$\mathbf{0 . 0 4 7 0 2 7 ~ M a x}$
0.041802
0.036577
0.031352
0.026126
0.020901
0.015676
0.010451
0.0052253
$\mathbf{0}$ Min

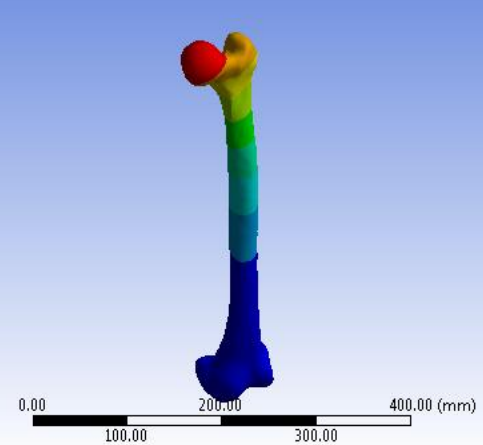

Figure 9: Maximum deformation:0.047027mm von-mises stresses in structural steel:
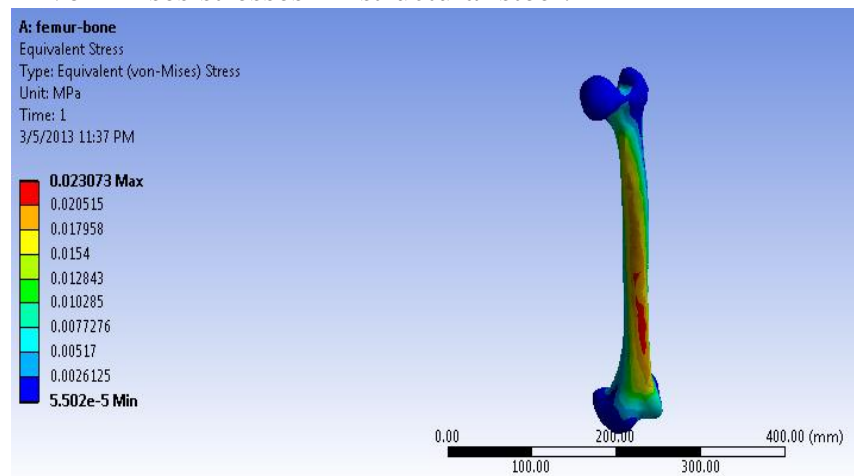

Figure 10: Max von-mises stresses in structural steel: 0.023073mpa 
Tabulated results for different materials at a constant load:

\begin{tabular}{|c|c|c|c|}
\hline Material & Load(kg) & Stresse(MPa) & Deformation(mm) \\
\hline \multirow[t]{3}{*}{ Ti-6Al-4V } & 550 & 0.01693 & 0.00063886 \\
\hline & 650 & 0.020009 & 0.00075501 \\
\hline & 750 & 0.023087 & 0.00087117 \\
\hline \multirow[t]{3}{*}{ Structural Steel } & 550 & 0.01692 & 0.034487 \\
\hline & 650 & 0.019996 & 0.040757 \\
\hline & 750 & 0.023073 & 0.047027 \\
\hline
\end{tabular}

\section{Results And Conclusion}

Comparison is done between Ti-6Al-4V and Structural Steel implant materials at different load conditions. At each load both stresses and deformations are evaluated. But the stresses of both materials are identically equal. When compared with deformation values Ti-6Al-4V shows less deformation results. hence Ti-6Al-4V is the best material in orthopedic implant surgeries.

- The results we have obtained are amazingly satisfactory due to less deformation of Ti-6Al-4V alloy.

- Ti-6Al-4V has excellent Bio-compatible properties along with physical properties which makes it an ideal implant material for fractures, when compared to stainless steel.

- $\quad \square \quad \square \mathrm{F} 6 \mathrm{Al}-4 \mathrm{~V}$ alloy being extremely light with less density does not have any adverseeffect on the patient and his movements ie., while lifting the leg, etc..

\section{ACKNOWLEDGMENT}

The satisfaction that accompanies the successful completion of any task would be incomplete without introducing the people who made it possible and whose constant guidance and encouragement crowns all efforts with success.

I express my sincere gratitude to Prof Dr S.V.Ramana and sri P.Govinda rao, Department of Mechanical Engineering. GMRIT Rajam. We are highly indebted to him for his guidance, timely suggestions at every stage and encouragement to complete this project work successfully.

Last but not the least we are deeply indebted to our family for all their support and who stood behind me to get this project completed in time. We are thankful to All Mighty for providing us with this opportunity.

\section{References}

[1] Amornsamankul, S.; Kaorapapong, K.; Wiwatanapataphee, B.(2010) : Three-Dimensional Simulation of Femur Bone and Implant in Femoral Canal using Finite Element Method, International Journal of Mathematics and Computers in Simulation, volume 4, pp 171-178.

[2] Bredbenner, T.L.; Eliason,T.D.; Potter,R.S.; Mason,R.L.; Havill,L.M.; Nicolella D.P. (2010) : Statistical Shape Modeling Describes Variation in Tibia and Femur Surface Geometry Between Control and Incidence Groups From The Osteoarthritis Initiative Database, Journal of Biomechanics ,43 1780-1786

[3] Cheung, G.; Zalzal, P. ; Bhandari, M.; Spelt, J.K. ; Papini, M. (2004) : Finite Element Analysis of a Femoral Retrograde Intramedullary Nail Subject to Gait Loading, Medical Engineering and Physics, 26 93-108.

[4] Coelho, P. G.; Fernandes, P. R.; Rodrigues, H. C.; Cardoso, J.B. ; Guedes, J.M. (2009) Numerical modeling of bone tissue adaptation-A hierarchical approach for bone apparent density and trabecular structure ,Journal of Biomechanics, 42 830-837

[5] Simulation of the mechanical behaviour of a HIP implant fixed to bone by cementation under arbitrary load-C R Oldani1 and A A Dominguez, Journal of Physics:conference series 90,Pg:142-146.

[6] Comparison of loading behaviour of femural stem of Ti-4Al-6V and cobalt-chromium alloys: a three dimensional finite element analysis-R.R. Clarke, I C Gruen, Sarmiento.

[7] T.A. Brown, L.Kohan, B.Ben-Nissan "Assessment By Finite Element Analyis Of The Impact Of Osteoporosis And Osteoarthritis On Hip Resurfacing", 5th ACAM 12-17 dec 2007.

[8] TOMMASINI S. M., NASSER P., SCHAFFLER M. B., JEPSEN K. J.Relationship between bone morphology and bone quality in male tibias: implications for stress fracture risk, J Bone Miner Res, 2005, 20:1372-1380.

[9] BENNELL K., MATHESON G., MEEUWISSE W., BRUKNER P., Risk factors for stress fractures, Sports Med, 1999, $28: 91-122$.

[10] GILADI M., MILGROM C., SIMKIN A., DANON Y., Stress fractures. Identifiable risk factors, Am J Sports Med, 1991, 19:647652

[11] Aligner, Weipert A. Designing principles ofcustom-made hip stems. Proc 3rd annual symposium on custom-made prostheses, Nice, 1990 .

[12] Amstutz HC. Complications oftotal hip replacement. C/in Orthop 1970; 72:123-37. 
[13] Capello WN. Fit the patient to the prosthesis : an argument against the routine use ofcustom hip implants. C/in Orthop 1989; 249:56-9.

[14] Engh CA, Bobyn JD. Bio/ogica/fixation in tota/ hip arthrop/asty. New Jersey: Slack Inc, 1985.

[15] Ericksen MF. Aging changes in the medullary cavity of the proximal femur in American Blacks and Whites. Am JPhys Anthropo/ $1979 ; 51: 563-9$. 